DOI: $10.15593 / 2224-9826 / 2015.1 .08$

УДК 624.154

\author{
А.Б. Пономарев \\ Пермский национальный исследовательский \\ политехнический университет, Пермь, Россия

\section{СВАЙНЫЕ ФУНДАМЕНТЫ КАК ЭЛЕМЕНТЫ УСТОЙЧИВОГО СТРОИТЕЛЬСТВА}

\begin{abstract}
Рассматриваются некоторые результаты исследований свайных фундаментов, которые были выполнены сотрудниками Пермского национального исследовательского политехнического университета в последние годы. Необходимо отметить, что полученные результаты комплексных исследований легли в основу различных подходов по проектированию и устройству свайных фундаментов как элементов устойчивого строительства. На основании экспериментальных исследований в разное время сотрудниками ПНИПУ были разработаны методы расчета осадок различных типов свай (призматических, конических, свай с раскрывающимися лопастями и т.п.). В данной статье более подробно рассматриваются результаты исследовании полых конических свай как одной из эффективных конструкций свайных фундаментов. Эти сваи представляют собой усеченный полый конус и изготовляются методом центрифугирования. Полые конические сваи рекомендуется применять при строительстве обычных промышленно-гражданских сооружений, расчет которых ведется из условия предельно допустимых деформаций, в геологических условиях, где слабые водонасыщенные грунты имеют мощность не более 10-12 м. Благодаря развитой боковой поверхности и действию расклинивающего эффекта применение фундаментов из полых конических свай позволяет экономить до 40 \% железобетона и до 15 \% арматуры по сравнению с известными конструкциями свай сплошного сечения. Удачным фактом практического внедрения конических свай является использование их при реконструкции тепловых городских станций. В этом случае предложенные сваи, по сравнению с обычными пирамидальными и призматическими сваями, оказались более экономичной конструкцией и позволили значительно удешевить стоимость строительства. В практике проектирования часто возникает необходимость рассчитывать осадки фундаментов во времени, так как разность осадок во времени может быть больше предельно допустимой величины. В статье приводится функция по определению осадки одиночной конической сваи в любой момент времени. Также рассматривается вопрос о действии горизонтальной нагрузки на сваю, приводятся результаты экспериментальных исследований, а также аналитические решения, которые легли в основу расчета предельной горизонтальной нагрузки на сваю.

Ключевые слова: экспериментальные исследования, свайные фундаменты, полые конические сваи, прогноз осадки во времени, горизонтальные нагрузки, определение предельной нагрузки на сваю, пример расчета.
\end{abstract}




\title{
A.B. Ponomarev
}

\author{
Perm National Research Polytechnic University, Perm, Russian Federation
}

\section{PILE FOUNDATIONS AS ELEMENTS OF SUSTAINABLE CONSTRUCTION}

This article discusses some of the results of studies of pile foundations, which were performed by employees of the Perm National Research Polytechnic University in recent years. It should be noted that the results of comprehensive studies formed the basis of different approaches for the design and installation of pile foundations, as part of sustainable development. On the basis of experimental studies at different times employees PNIPU methods have been developed for calculating different types of sediment piles (prismatic, conical, with pull-down piles blades, etc.). This article looks more closely at the results of a study of hollow conical piles, as one of the most effective designs of pile foundations. These piles are truncated hollow cone and manufactured by centrifugation. Hollow conical piles are recommended for the construction of conventional industrial and civil buildings, the calculation of which is carried out from the condition of maximum allowable strain in geological conditions, where the weak saturated soils have a capacity of not more than 10-12 m. Due to the developed lateral surface and the action of wedging effect of the use of foundations hollow conical piles can save up to $40 \%$ and the concrete reinforcement to $15 \%$ in comparison with known designs of piles of solid section. Fact the best practical implementation of conical piles is their use in the reconstruction of urban thermal stations. In this case, the pile offered compared to conventional prismatic pyramidal piles and be more economical construction and have significantly reduce cost. In practice the design is often necessary to count the time bases precipitates as precipitate time difference may be larger maximum allowable value. The article provides a function to determine the rainfall single conical pile at any time. The article also discusses the question of the effect of the horizontal load on the pile, the results of experimental research, and analytical solutions, which formed the basis for calculating the limit horizontal load on the pile.

Keywords: experimental studies, pile foundations, hollow conical piles forecast rainfall over time, horizontal loads, the definition of the limit load on the pile, an example calculation.

Начиная с 60-х гг. свайные фундаменты нашли широкое применение в России, в различных регионах на них возводилось до 40-70 \% зданий. Это связано с повышением этажности сооружений, увеличением их габаритов, возрастанием нагрузок, передаваемых на единицу площади, использованием площадок со сложными инженерно-геологическими условиями [1]. В этих условиях свайные фундаменты являются наиболее целесообразными и экономически выгодными.

\section{1. Основные результаты исследований свайных фундаментов}

За последние 50 лет в Пермском национальном исследовательском политехническом университете (ПНИПУ) были проведены комплексные экспериментально-теоретические исследования в полевых и лабораторных условиях, в грунтах различных типов: глинистых - от текучей до тугопластичной консистенции; песчаных - рыхлых и средней плот- 
ности, опытное строительство различных зданий и сооружений на таких грунтах [2].

Выполненные сотрудниками ПНИПУ исследования позволили установить:

1. Размеры зон уплотнения по боковой поверхности и под острием свай и фундаментов при их погружении в различные грунты.

2. Изменение модуля деформации, объемной массы и сцепления грунта в уплотненной зоне свайных фундаментов.

3. Закономерности развития осадок центрально и внецентренно загруженных свайных фундаментов в зависимости от расстояния между сваями, их длины, грунтовых условий. У одиночных свай после мобилизации сил трения осадки имеют «правильный характер». В интервале 1/3-2/3 предельной нагрузки осадки фундаментов (3-10 мм) в несколько раз (до 5-7) больше осадок одиночных свай (1-2 мм). При работе свай в составе фундамента резкой потери несущей способности не наблюдается. Осадки возрастают плавно, при 25-40 мм кривые «нагрузка - осадка» фундаментов пересекают аналогичные кривые одиночных свай. Несущую способность фундаментов можно правильно определить только исходя из предельно допустимых осадок оснований и фундаментов для соответствующих зданий и сооружений. При осадках, равных предельным значениям совместной деформации основания и сооружения, нагрузки могут быть увеличены на 20-50 \%, а при контакте ростверка с грунтом - до двух раз по сравнению с существующими действующими нормативными документами.

4. Зависимость несущей способности свайных фундаментов от различных грунтовых условий при действии горизонтальной нагрузки.

5. Напряжения под ростверком, в межсвайном пространстве и в активной зоне фундамента (зоны деформации). Выявлена роль ростверка в несущей способности различных свайных фундаментов. При расстоянии между сваями три диаметра и длине свыше 9 м доля ростверка в несущей способности составляет 10-12\%, а при расстоянии шесть диаметров и длине свай 5-8 м до 35-40 \%. При осадках фундаментов, близких к предельным для зданий, напряжения в активной зоне не превышали несущую способность грунтов основания с учетом изменения свойств грунтов в результате забивки свай.

6. Физическую сущность процесса увеличения несущей способности свайных фундаментов во времени при их работе в водонасы- 
щенных глинистых грунтах. В четвертичных водонасыщенных суглинках и глинах несущая способность увеличивается в течение 40-45 сут у одиночных свай и 60-100 сут у фундаментов из 16-25 свай. Несущая способность в 2,5 раза выше первоначальной и в 1,4-1,5 раза больше той, которая наблюдается при «отдыхе» свай в течение 6 сут.

7. Реологические параметры оснований активной зоны фундаментов в зависимости от грунтовых условий, длины свай, параметров фундамента и величины действующей нагрузки.

На основании экспериментальных исследований в разное время сотрудниками ПНИПУ были разработаны методы расчета осадок различных типов свай (призматических, конических, свай с раскрывающимися лопастями и т.п.) [3].

\section{2. Исследования полых конических свай}

Одной из эффективных конструкций сваи повышенной несущей способности являются полые конические сваи [4]. Эти сваи представляют собой усеченный полый конус и изготовляются методом центрифугирования. Полые конические сваи рекомендуется применять при строительстве обычных промышленно-гражданских сооружений, расчет которых ведется из условия предельно допустимых деформаций, в геологических условиях, где слабые водонасыщенные грунты имеют мощность не более 10-12 м. Благодаря развитой боковой поверхности и действию расклинивающего эффекта применение фундаментов из полых конических свай позволяет экономить до $40 \%$ железобетона и до $15 \%$ арматуры по сравнению с известными конструкциями свай сплошного сечения. Удачным фактом практического внедрения конических свай является использование их при реконструкции тепловых городских станций. В этом случае предложенные сваи, по сравнению с обычными пирамидальными и призматическими сваями, оказались более экономичной конструкцией и позволили значительно удешевить стоимость строительства.

Учитывая, что строительство вновь возводимых объектов происходило в стесненных условиях предприятий непрерывного технологического цикла, повышенного класса ответственности, для прогноза несущей способности, осадок и анализа напряженно-деформированного состояния активной зоны полых конических свай использовался метод конечных элементов (МКЭ) [5], который был реализован в пакете при- 
кладных программ PLAXIS, разработанных консорциумом европейских организаций в развитие Европейских норм Еврокод-7. Основным расчетным элементом программы PLAXIS является 15-узловой треугольный изопараметрический элемент четвертого порядка интерполяции. В таком элементе перемещения определяются во всех 15 узлах, а напряжения - в 12 точках, получаемых в результате точного интегрирования. Целью использования МКЭ являлась необходимость рассмотрения системы «свая - грунт» с учетом нелинейности работы грунтового массива и возможности принимать во внимание пластические свойства грунта. Численное моделирование с помощью метода конечных элементов работы полых конических свай с окружающим грунтом включало следующие задачи:

- действие вертикальной сосредоточенной силы на одиночную сваю;

- действие горизонтальной сосредоточенной силы на одиночную сваю;

- действие вертикальной нагрузки на ленточный фундамент;

- действие вертикальной нагрузки на куст;

- действие горизонтальной нагрузки на куст.

Задачи решались в условиях осевой симметрии и плоской деформации. В качестве расчетной использовалась «продвинутая» модель Мора - Кулона, которая, в отличие от классической модели, учитывает влияние жесткости материала (грунта) на уровень предельных сдвиговых напряжений. Также в «продвинутой» модели после интенсивного сдвига грунта критическая плотность уменьшается и делатансия имеет предельную величину.

Анализ напряженно-деформированного состояния активной зоны фундаментов из полых конических свай методом конечных элементов на основе пакета прикладных программ PLAXIS позволил рассмотреть работу системы «грунтовое основание - фундамент» с учетом нелинейной работы грунта. Это дало возможность: учитывать неоднородность напластования грунтов основания; производить совместный расчет системы «основание - свайный фундамент» с учетом формирования зон уплотнения грунтов при забивке и загружении полых конических свай; выявлять зоны развития пластических деформаций с учетом роста нагрузки на сваю. Результаты решения методом конечных элементов достаточно хорошо согласуются с опытными данными, полученными экспериментальным путем. Расхождения между теоретическими и опытными значениями составляют 10-25\%. 


\section{3. Прогноз осадки свай во времени}

В практике проектирования часто возникает необходимость рассчитывать осадки фундаментов во времени, так как разность осадок во времени может быть больше предельно допустимой величины. Кроме того, большое значение имеет скорость протекания осадок во времени. При медленном возрастании осадок фундаментов (даже значительных по величине) надземные конструкции зданий способны деформироваться пластически, без нарушения сплошности элементов конструкции. Если же скорость осадок велика, то может произойти хрупкое разрушение отдельных элементов, что приведет к недопустимым деформациям всего здания. Поэтому расчет осадок во времени является одним из составных вопросов проектирования фундаментов по предельным состояниям [6].

В зависимости от свойств грунтов и их состояния для расчета осадок фундаментов во времени принимают различные теории: теорию ползучести и теорию фильтрационной консолидации с учетом сжимаемости поровой жидкости, структурной прочности грунта при сжатии, начального градиента напора, параметров ползучести [7].

При работе свай в водонасыщенных глинистых грунтах текучеи мягкопластичной консистенции, содержащих в своих порах свободную воду и обладающих малыми структурными связями, осадка происходит в основном за счет отжатия воды из пор [8]. Деформации, вызванные ползучестью скелета грунта, в данном случае незначительны, и осадки во времени можно получить, решая задачи теории фильтрационной консолидации.

В конечном итоге была получена функция по определению осадки одиночной конической сваи в любой момент времени, представленная в виде

$$
S=\frac{1}{0,078} \operatorname{arctg} \frac{P}{85}\left[1+3,402\left(1+\ell^{-t}\right)\right],
$$

где $P$ - величина нагрузки, соответствующая времени $t$, отсчитываемом от начала нагружения сваи.

Однако данная формула дает хорошую сходимость результатов с экспериментом на начальных стадиях загружения, при конечных ступенях нагрузки мы имеем значительные расхождения, а именно занижение осадки по сравнению с экспериментом. Для корректировки формулы введем константы, после чего она примет следующий вид: 


$$
S=\frac{1}{0,078} \operatorname{arctg} \frac{P}{85}\left[1+3,402 \cdot 2\left(1+\ell^{-t \cdot 0,1}\right)\right] .
$$

В этом случае мы имеем сходимость результатов на начальной стадии загружения с превышением на 15-20\%, и на конечной стадии загружения с уменьшением результатов расчетных величин осадок по сравнению с экспериментальными данными на 30-35\%. Результаты сравнения расчетных и экспериментальных значений осадок представлены на рис. 1.

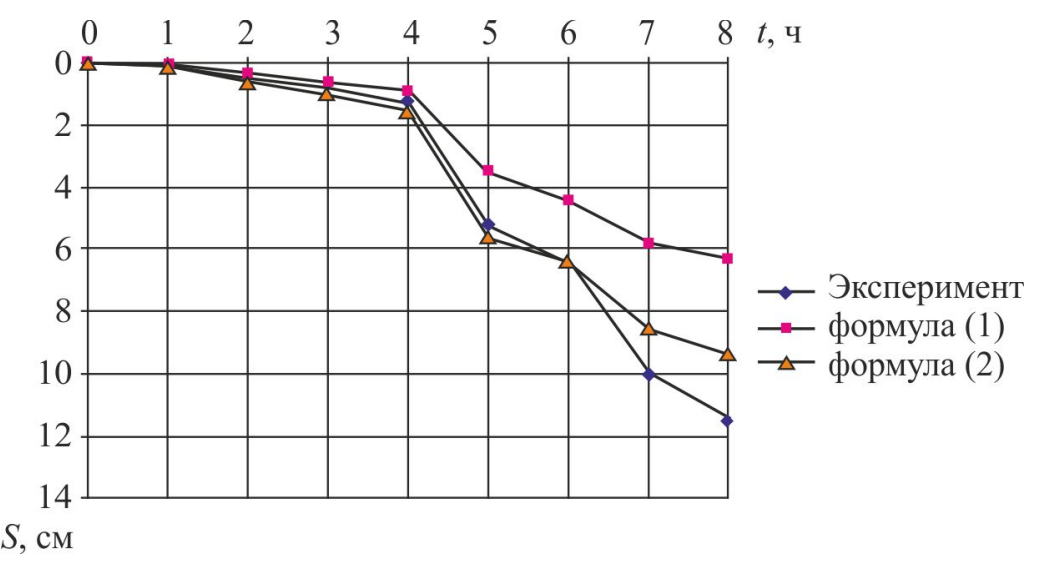

Рис 1. Сравнение результатов экспериментальных и расчетных значений при различных стадиях загружения

\section{4. Учет горизонтальных нагрузок на свайные фундаменты}

Несмотря на обилие экспериментальных данных, выполненных различными авторами и многообразием существующих методов расчета свайных фундаментов на горизонтальные нагрузки, влияние горизонтальных нагрузок на общую устойчивость возводимых объектов строительства по сей день остается актуальной по причине разнородности мнений исследователей и несовершенности методов расчета [9]. В результате этого фундаменты проектируются с большими запасами либо не обеспечивают требуемой несущей способности свай [10].

На рис. 2 представлены результаты испытаний одиночных трехметровых свай (полых конических и призматических) горизонтальными статическими нагрузками на экспериментальной площадке сложен- 
ной суглинками мягкопластичной консистенции со следующими характеристиками: удельный вес $\gamma=18,3 \ldots 20,6$ кН// ${ }^{3}$; природная влажность $\omega=0,26 \ldots 0,36$; коэффициент пористости $e=0,70 \ldots 0,82$; удельное сцепление $c=0,015 \ldots 0,024$ МПа; угол внутреннего трения $\varphi=15,6 \ldots 17^{\circ}$; модуль деформации $E=6,1 \ldots 9,7$ МПа.

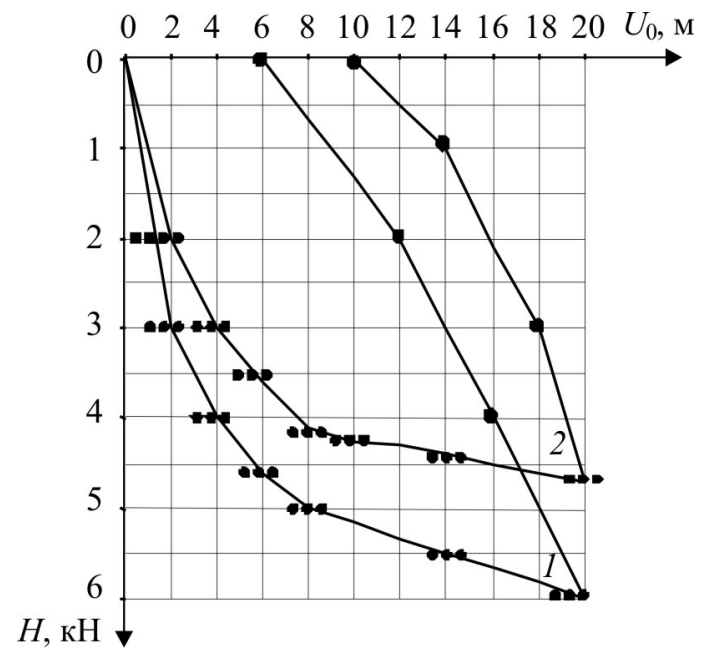

Рис. 2. Результаты испытаний свай на горизонтальную нагрузку:

1 - коническая свая; 2 - призматическая свая

Анализ графиков говорит о том, что сваи включаются в работу на первых ступенях нагружения, и до перемещений голов свай $U_{0}=2 \ldots 3$ мм график зависимости нагрузка - перемещения носит линейный характер. Второй участок отличается резким увеличением кривизны и отражает нелинейный характер зависимости между нагрузками и перемещениями.

Величина несущей способности свай от действия горизонтальной нагрузки определялась при перемещении головы сваи $U_{0}=10$ мм. Таким образом, величина несущей способности полой конической сваи от действия горизонтальной силы составила $F_{h}=52 \mathrm{\kappa H}$, а призматической сваи $-F_{h}=43$ кН. Разница между величинами составляет $20 \%$. Следовательно, сопротивление свай горизонтальной нагрузке зависит от геометрических характеристик поперечного сечения ствола сваи и ее жесткости. В процессе испытаний свай горизонтальной нагрузкой были выполнены наблюдения за деформациями грунта, вызванные смещением свай. При начальных ступенях нагрузки, когда голова сваи 
переместилась на 3-5 мм, на поверхности грунта около сваи появились еле заметные радиальные трещины. С дальнейшим перемещением голов свай от нагрузки трещины увеличивались, их длина достигала 30-40 см, ширина - до 3 см, максимальная глубина - 15 см. Между гранями конических свай и грунтом в месте приложения нагрузки образовалась серповидная щель, а у призматических - неглубокая полость. Причем эта щель увеличивалась по мере нагружения свай. Обрушения грунта в щель не происходило. После снятия нагрузок произошло упругое возвращение полой конической сваи на прежнее место, щель практически закрылась, трещин не осталось. А в случае с призматической сваей упругого возвращения не произошло, образовавшаяся полость закрылась лишь частично. Это позволяет говорить о том, что конические сваи гораздо лучше работают на горизонтальные нагрузки, нежели призматические, и по своим прочностным и упругим качествам значительно превосходят сваи сплошного квадратного сечения.

На рис. 3 приведены результаты испытаний одиночных свай и кустов из пяти конических свай на действие горизонтальной нагрузки. Проведенные исследования несущей способности одиночных полых конических свай и в составе кустов, объединенных ростверком, при одинаковой глубине погружения, свидетельствуют о том, что несущая способность свай в составе куста выше, чем у одиночной сваи. В частности, для одиночной сваи она составляет $F_{h}=53$ кН, а для сваи куста $F_{h}=76$ кН. Превышение составляет $43 \%$. Повышение несущей способности свай в кусте по сравнению с одиночной может быть объяснено вовлечением в работу большого объема грунта. Также из графиков видно, что на первых ступенях нагружения свай и свайных кустов, не превышающих горизонтальных деформаций 3 мм, зависимости «нагрузка - перемещение» имеют линейный характер. При возрастании величин нагрузок графики переходят в плавные очертания.

При расчете свай на действие горизонтальной нагрузки постановка задачи сводилась к тому, что даны известные геометрические и прочностные параметры «жесткой» сваи и грунтового массива, величина перемещения головы сваи $U_{0}$ от горизонтальной нагрузки $H$, приложенной в уровне поверхности грунта при $z=0$ [11]. Необходимо найти предельную горизонтальную силу $H$. 


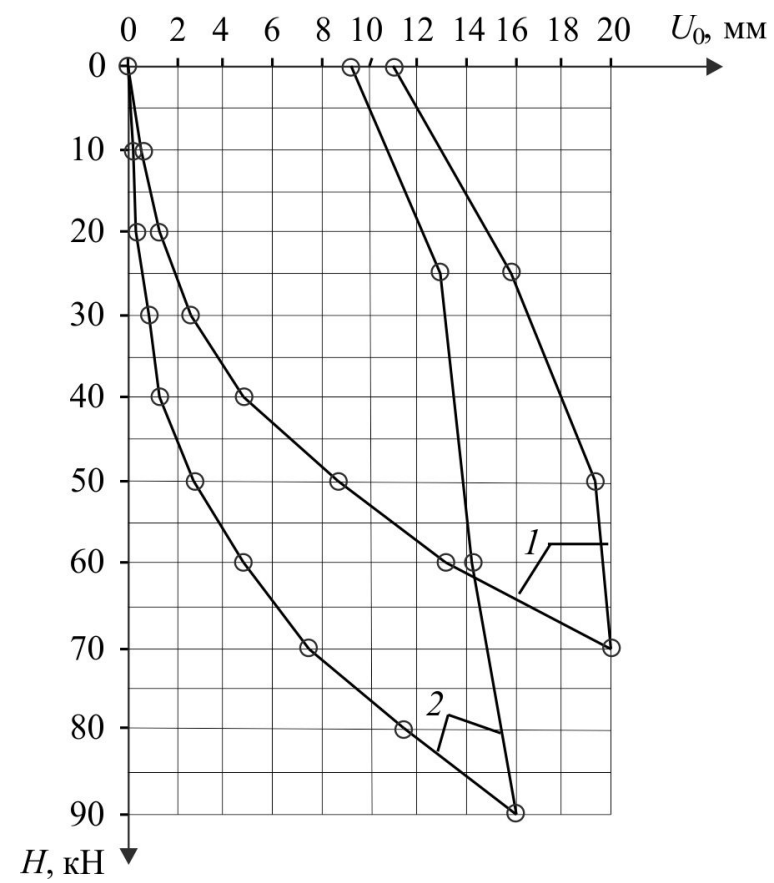

Рис. 3. Графики зависимости перемещений головы свай от горизонтальной нагрузки: 1 - одиночная коническая свая; 2 - свая куста из пяти свай

В этом случае предельная горизонтальная сила:

$$
H=F_{\text {отп }}+F_{\text {тр }},
$$

где

$$
F_{\text {отп }}=\int_{0}^{l} y_{1}(z) b(z) c(z) d(z)
$$

есть сила отпора окружающего грунта по передней грани сваи при ее повороте вокруг точки нулевых перемещений при действии на нее горизонтальной нагрузки $H$;

$$
F_{\text {тр }}=2 \int_{0}^{l} f_{\text {тр }}(z) a(z) d(z)
$$

есть сила трения окружающего грунта по двум боковым граням сваи, возникающая при перемещении сваи от действия горизонтальной нагрузки $H ; y(z)$ - перемещение сваи на глубине $z ; y_{1}(z)$ - та часть перемещения сваи на глубине $z$, при которой возникает отпор грунта по 
ширине сваи; $b(z)$ - ширина сваи на глубине $z ; c(z)$ - коэффициент постели на глубине $z ; a(z)$ - ширина участка, по которому действует сила трения; $f_{\text {тр }}(z)$ - удельная сила трения на глубине $z$.

Если в точке $z=z_{0}$ сдвиг сваи будет равен нулю (точка нулевых перемещений, находящаяся на глубине $z_{0}=2 l / 3$ ), то

$$
Y(z)=\frac{Y_{0}\left(Z_{0}-Z\right)}{Z_{0}}
$$

и при $z>z_{0}, y(z)<0$.

Примем

$$
f_{\text {тр }}(z)=\left\{\begin{array}{l}
\frac{y(z)}{y_{\text {т }}} f_{\text {тр } \max }(z),|y(z)| \leq y_{\text {т }} \\
\frac{y(z)}{|y(z)|} f_{\text {тр } \max }(z),|y(z)| \geq y_{\mathrm{r}},
\end{array}\right.
$$

в данном случае мы принимаем, что сила трения с увеличением сдвига нарастает пропорционально $y(z)$, доходит до $y_{\mathrm{T}}$, а затем перестает расти.

Принимаем

$$
y_{1}(z)=\left\{\begin{array}{c}
y(z),|y(z)| \leq A y_{m} \\
\frac{y(z) A y_{m}}{|y(z)|},|y(z)| \geq A y_{m},
\end{array}\right.
$$

где $y_{m}$ - величина перемещений (сдвига) участка сваи, при которых силы трения по боковым граням достигают на этом участке максимального значения; $A$ - безразмерный коэффициент, принимаемый в зависимости от геометрии сечения сваи: для круглых свай $A=1,8 \ldots 2$, а для квадратного сечения - 1,5-1,8.

Мы принимаем, что при перемещении сваи не более $A y_{m}$ силы отпора грунта пропорциональны горизонтальным перемещениям, а при увеличении перемещения свыше $A y_{m}$ - перестают расти по причине возникновения пластических деформаций в грунте.

Для свай квадратного сечения (призматической или пирамидальной) $a(z)=b(z)=d(z)$, где $d(z)-$ сторона квадрата (сечения сваи) на глубине $z$. 
Величина $z_{0}$ определяется из условия

$$
\begin{aligned}
& y=\int_{0}^{l} z\left(y_{1}(z) b(z) c(z)+\right. \\
& +2 f_{\text {тр }}(z) a(z) d(z)=0,
\end{aligned}
$$

означающего, что момент сил отпора грунта и трения относительно точки $z=0$ равен нулю, так как этот момент уравновешивает момент силы $H$, действующей при $z=0$.

С учетом результатов выполненных нами исследований, а также на основе работ других исследователей примем, что сила предельного трения окружающего грунта по боковой поверхности сваи от действия горизонтальной нагрузки определяется зависимостью $f_{\text {тр } \max }=\tau \xi$. Здесь $\tau$ - предельное сопротивление грунта сдвигу на контакте с боковой поверхностью сваи, $\xi-$ коэффициент бокового давления грунта [12]. Предельное сопротивление грунта сдвигу определяется по известной зависимости Ш. Кулона:

$$
\tau=\sigma_{x} \operatorname{tg} \varphi+c
$$

где $\sigma_{x}-$ нормальные напряжения.

Для облегчения выполнения инженерных расчетов по определению горизонтальной силы, действующей на коническую сваю, значения силы $H$ были табулированы в зависимости от коэффициента пропорциональности грунта $K=5000,10000,15000,20000$ кН/м, угла сбега боковых граней $\alpha=1^{\circ} ; 1,5^{\circ} ; 2^{\circ}$; горизонтального смещения $U_{0}=0,5 ; 1,0$; 1,$5 ; 2,0$ см, силы предельного трения грунта $f_{\text {тр мах }}=5,10,15,20,25,30$, $35,40,45,50$ и приведенной длины сваи $L / d_{0}=5,10,15,20$. Фрагмент общей табуляции представлен в таблице.

Значение горизонтальной силы $H$, действующей

на коническую сваю

\begin{tabular}{|c|c|c|c|c|c|}
\hline \multicolumn{5}{|c|}{$d_{0}=0,29 ; \alpha=1,5^{\circ} ; k=10000$} \\
\hline \multirow{2}{*}{$f_{\text {тp } \max }$} & \multirow{4}{*}{$l / d_{0}$} & 0,005 & 0,010 & 0,015 & 0,020 \\
\hline \multirow{3}{*}{20,00} & 5,0 & 7,2 & 8,7 & 9,2 & 9,4 \\
\cline { 2 - 6 } & 10,0 & 20,1 & 25,5 & 27,4 & 28,1 \\
\cline { 2 - 6 } & 15,0 & 39,8 & 52,1 & 56,4 & 58,1 \\
\cline { 2 - 6 } & 20,0 & 67,6 & 90,2 & 98,2 & 101,3 \\
\hline
\end{tabular}




\section{5. Алгоритм и пример расчета конической сваи}

Общий алгоритм расчета конических свай на действие горизонтальной нагрузки будет следующим:

1. Задаемся геометрическими параметрами сваи:

$\alpha$ - угол сбега боковых граней; $L$ - длина сваи; $d_{0}$ - диаметр острия сваи.

2. Определяем параметры грунтового основания:

$K$ - коэффициент пропорциональности грунта, $\gamma_{n}$ - коэффициент условий работы сваи.

3. Определяем силу предельного трения окружающего грунта по боковой поверхности сваи от действия горизонтальной нагрузки:

$$
f_{\text {тр } \max }=\tau \xi,
$$

где $\tau$ - предельное сопротивление грунта сдвигу на контакте с боковой поверхностью сваи; $\xi$ - коэффициент бокового давления грунта.

Предельное сопротивление грунта сдвигу определяем по формуле (10):

$$
\tau=\sigma_{x} \operatorname{tg} \varphi+c
$$

где $\sigma_{x}$ - нормальные напряжения; $\varphi$ - угол внутреннего трения грунта; $c$ - удельное сцепление грунта.

4. Определяем величину горизонтальной силы $H$, приложенной к голове сваи, при максимальном заданном горизонтальном перемещении $U_{0}$.

\section{Пример}

Определить величину горизонтальной силы $H$, приложенной к голове конической круглой сваи с углом сбега боковых граней $\alpha=1,5^{\circ}$, длиной 4,35 м, с диаметром острия 0,29 м при максимальном горизонтальном перемещении 1,0 см. Свая забита в суглинки мягкопластичные с коэффициентом пропорциональности $K=10000$ кН/м ${ }^{4}$, удельным весом $\gamma=16,2 \mathrm{\kappa H} / \mathrm{m}^{3}$, углом внутреннего трения $\varphi=15^{\circ}$, удельным сцеплением $c=18$ кПа.

Решение:

1. Коэффициент условий работы принимаем $\gamma_{n}=1,0-$ свая «жесткая».

2. Определяем предельное трение окружающего грунта по боковой поверхности сваи: 


$$
\tau=\sigma_{x} \operatorname{tg} \varphi+c=35,2 \operatorname{tg} 15+18=27,4 \text { кПа, }
$$

где $\sigma_{x}=16,2 \cdot 2,175=35,2$ кПа - нормальные напряжения.

$$
f_{\text {тр } \max }=\tau \xi=27,4 \cdot 0,73=20 \kappa \Pi а,
$$

где $\xi=0,73$ - коэффициент бокового давления грунта.

3. Находим приведенную длину сваи $L / d_{0}=4,35 / 0,29=15$.

4. По таблице определим для $U_{0}=1,0$ см величину $H=52,1$ кН.

\section{6. Основные выводы}

1. Выполненные в различные годы исследования работы свайных фундаментов различных типов легли в основу подхода, обеспечивающего устойчивость строительства в сложных инженерно-геологических условиях.

2. Конические сваи обладают высокими технико-экономическими показателями, эффективность их применения будет возрастать с увеличением длины свай.

3. Существенное влияние на осадки свай в водонасыщенных глинистых грунтах оказывает фактор времени. Для прогноза таких осадок следует использовать известные выражения теории ползучести и теории фильтрационной консолидации.

4. Важным фактором является влияние горизонтальных нагрузок на общую устойчивость возводимых объектов строительства. При расчете свай на действие горизонтальной нагрузки рекомендуется использовать расчетную схему «жесткой» сваи и известные геометрические и прочностные параметры самой свайной конструкции.

\section{Библиографический список}

1. Tomlinson M., Woodward J. Pile design and construction practice. London; New York: Taylor \& Francis, 2008. - 551 p.

2. Бартоломей А.А., Омельчак И.М., Юшков Б.С. Прогноз осадок свайных фундаментов. - М.: Стройиздат, 1994. - 384 с.

3. Справочник геотехника. Основания, фундаменты и подземные сооружения / под общ. ред. В.А. Ильичева и Р.А. Мангушева. - М.: Изд-во АСВ, 2014. - 728 с.

4. Пономарев А.Б. Экспериментально-теоретические основы прогноза осадок и несущей способности фундаментов из свай распорных конструкций: автореф. дис. ... д-ра техн. наук. - Пермь, 1999. - 32 с. 
5. Bartolomei A.A., Ponomarev A.B. Experimental investigations and prediction of settlements of conical-pile foundations // Soil Mechanics and Foundation Engineering. - 2001. - T. 38, no. 2. - C. 42-50. DOI: 10.1023/A: 1010422029681

6. Cock F.De., Legrand C. Design of axially loaded piles. European practice // Proceedings of the ERTC3 seminar. - Brussels. Belgium. A.A. Balkema, 1997. -377 p.

7. Katzenbach R., Darmstadt Geotechnics // № 18 International conference on deep foundations - CPRF and Energy piles. - Frankfurt am Main, 2009. - $371 \mathrm{p}$.

8. Пономарев А.Б., Безгодов М.А. Несущая способность забивных свай в слабых водонасыщенных грунтах с учетом фактора времени // Вестник Пермского национального исследовательского политехнического университета. Строительство и архитектура. - 2014. № 1. - С. 7-15

9. Готман А.Л. Безростверковые свайные фундаменты промышленных зданий и сооружений и общая методология их расчета: автореф. дис. ... д-ра техн. наук. - Уфа, 1995. - 34 с.

10. Brandl H. Stutzbauwerke und konstruktive hangsicherungen. Sonderdruck aus dem grundbau-taschenbuch, teil 3, grundungen. - Ernst \& Sohn, 2001. - P. 495-655.

11. Пономарев А.Б., Соловьев А.В., Богомолова О.А. К вопросу определения расчетной нагрузки на сваю // Актуальные проблемы геотехники: сб. ст., посвященный 60-летию профессора А.Н. Богомолова / под ред. А.Н. Богомолова, А.Б. Пономарева. - Волгоград, 2014. - С. 159-165.

12. Vanicek I. Sustainable construction. Czech technical university in Prague. - Praha, 2011. - 162 p.

\section{References}

1. Tomlinson M., Woodward J. Pile design and construction practice. London and New York: Taylor \& Francis, 2008. 551 p.

2. Bartolomei A.A., Omelchak I.M., Iushkov B.S. Prognoz osadok svainykh fundamentov [Forecast settlement pile foundations]. Moscow: Stroiizdat, 1994. 384 p.

3. Spravochnik geotehnika. Osnovaniia, fundamenty i podzemnye sooruzheniia [Directory geotechnics. Bases, foundations and underground structures]. Moscow: Assotsiatsiia stroitel'nykh vuzov, 2014. 728 p. 
4. Ponomarev A.B. Eksperimentalno-teoreticheskie osnovy prognoza osadok i nesushchei sposobnosti fundamentov iz svai raspornykh konstruktsii [Experimental and theoretical basis of the prediction residue and bearing capacity of foundation piles struts]. Abstract of the thesis Doctor of Technical Sciences, Perm, 1999. 32 p.

5. Bartolomei A.A., Ponomarev A.B. Experimental investigations and prediction of settlements of conical-pile foundations. Soil Mechanics and Foundation Engineering, 2001. vol. 3, no. 2. pp. 42-50. DOI: 10.1023/A: 1010422029681

6. Cock F.De., Legrand C. Design of axially loaded piles. European practice. Proceedings of the ERTC3 seminar. Brussels, Belgium, A.A.Balkema, 1997. 377 p.

7. Katzenbach R. Darmstadt Geotechnics. 18 International conference on deep foundations - CPRF and Energy piles. Frankfurt am Main, 2009. $371 \mathrm{p}$.

8. Ponomarev A.B., Bezgodov M.A. Nesushchaia sposobnost' zabivnykh svai $\mathrm{v}$ slabykh vodonasyshchennykh gruntakh $\mathrm{s}$ uchetom faktora vremeni [The bearing capacity of piles in soft water-saturated clayey soils considering the time factor]. Vestnik Permskogo natsional'nogo issledovatel'skogo politekhnicheskogo universiteta. Stroitel'stvo i arkhitektura, 2014, no. 1, pp. 7-15.

9. Gotman A.L. Bezrostverkovye svainye fundamenty promyshlennykh zdanii i sooruzhenii i obshchaia metodologiia ikh rascheta [Pile foundations without grillage for industrial buildings and structures and the General methodology of their calculation]. Abstract of the thesis Doctor of Technical Sciences, Ufa, 1995. 34 p.

10. Brandl H. Stutzbauwerke und konstruktive hangsicherungen. Sonderdruck aus dem grundbau-taschenbuch, teil 3, grundungen. Ernst \& Sohn, 2001, pp. 495-655.

11. Ponomarev A.B., Solov'ev A.V., Bogomolova O.A. K voprosu opredeleniia raschetnoi nagruzki na svaiu [To the question of determining the estimated load on the pile]. Sbornik statei, posviashchennyi 60-letiiu professora A.N. Bogomolova "Aktual'nye problemy geotekhniki”, Volgograd, 2014, pp. 159-165.

12. Vanicek I. Sustainable construction. Praha: Czech technical university in Prague, 2011. 162 p.

Получено 22.01.2015 


\section{Сведения об авторе}

Пономарев Андрей Будимирович (Пермь, Россия) - доктор технических наук, профессор, заведующий кафедрой «Строительное производство и геотехника» Пермского национального исследовательского политехнического университета (614990, г. Пермь, Комсомольский пр., 29, e-mail: spstf@ pstu.ru).

\section{About the author}

Andrei B. Ponomarev (Perm, Russian Federation) - Doctor of Technical Sciences, Professor, Head of Department of Construction Technology and Geotechnics, Perm National Research Polytechnic University (29, Komsomolsky av., Perm, 614990, Russian Federation, e-mail: spstf@ pstu.ru). 